\title{
3D Heat transfer Simulation of an injection mold: comparison between ANSYS Workbench and ANSYS Mechanical APDL
}

Hugo Miguel Silva ( $\sim$ b7802@dep.uminho.pt)

University of Minho School of Engineering: Universidade do Minho Escola de Engenharia

Leandro Fernandes

University of Minho School of Engineering: Universidade do Minho Escola de Engenharia

Hugo Luís Rodrigues

University of Minho School of Engineering: Universidade do Minho Escola de Engenharia

João Tiago Noversa

University of Minho School of Engineering: Universidade do Minho Escola de Engenharia

António José Pontes

University of Minho School of Engineering: Universidade do Minho Escola de Engenharia

\section{Research Article}

Keywords: conformal cooling, injection molding, computer aided engineering, Design Optimization

Posted Date: November 2nd, 2021

DOI: https://doi.org/10.21203/rs.3.rs-1017293/v1

License: (9) This work is licensed under a Creative Commons Attribution 4.0 International License.

Read Full License 
Noname manuscript No.

(will be inserted by the editor)

\title{
3D Heat transfer Simulation of an injection mold: comparison between ANSYS Workbench and ANSYS Mechanical APDL
}

\author{
Hugo Miguel Silva · Leandro Fernandes · Hugo Luís Rodrigues · João Tiago Noversa · \\ António José Pontes
}

IPC- Institute for Polymers and Composites

DEP-Department of Polymer Engineering University of Minho

Campus de Azurém 5100 - 061 Guimarães, Portugal

*corresponding author, email: b7802 @dep.uminho.pt

Received: date / Accepted: date

\begin{abstract}
Because of recent advancements in additive manufacturing, fabricating conformal cooling channels (CCCs) has become easier and more economical. In the injection molding process, CCCs provide higher cooling performance than standard (straight drilled) channels. The major reason for this is that CCCs may follow the courses of the molded geometry, whereas typical channels created using traditional machining processes cannot. Using CCCs can reduce thermal strains and warpage while also improving cycle time and achieving a more uniform temperature distribution. CCC, on the other hand, has a more complicated design procedure than traditional channels. Simulations using computer-aided engineering (CAE) are critical for achieving an effective and cost-effective design. This article compares two ANSYS modules for the purpose of validating results. It can be inferred that the two modules produce similar results for models with fine mesh. As a result, the ANSYS module to work on should be chosen depending on the job's goal as well as the CAD geometry's complexity.
\end{abstract}

Keywords: conformal cooling; injection molding; computer aided engineering; Design Optimization

\footnotetext{
Hugo Miguel Silva

IPC Institute for Polymers and Composites DEP Department of Polymer Engineering, University of Minho, Campus de Azurém, 5100 - 061, Guimarães, Portugal

Tiago Noversa

IPC Institute for Polymers and Composites DEP Department of Polymer Engineering, University of Minho, Campus de Azurém, 5100 - 061, Guimarães, Portugal

Leandro Fernandes

IPC Institute for Polymers and Composites DEP Department of Polymer Engineering, University of Minho, Campus de Azurém, 5100 - 061, Guimarães, Portugal

Hugo Rodrigues

IPC Institute for Polymers and Composites DEP Department of Polymer Engineering, University of Minho, Campus de Azurém, 5100 - 061, Guimarães, Portugal

António Pontes

IPC Institute for Polymers and Composites DEP Department of Polymer Engineering, University of Minho, Campus de Azurém, 5100 - 061, Guimarães, Portugal
} 


\section{Introduction}

CCCs in injection molds have received a lot of attention in terms of design and modeling. A variety of simulation software was used to examine mold and channel designs. In 2005, Dimla et al. [1] used Moldflow analysis in I-DEASTM to find the best channel position. ABM Saifullah and SH Masood investigated the "part cooling time" using ANSYS thermal analysis modules [2]. In 2009, the same group of researchers used MPI simulation modules to evaluate parts and compare the results for conventional and quadratic CCC profiles, determining that conformal channels cool 38 percent faster than conventional channels [3]. To establish the mold temperature, Gloinn et al. from Ireland performed a FEM analysis with ABS polymer as the molten material and a cooling water inlet [4]. In the work [5], the authors investigated the thermal impacts of cooling channel design on the injection molding process using Moldflow Plastic Insight 3.1 in a 2007 study. The authors presented a ground-breaking approach for CC design consistency. The benefits of a cooling loop were verified by Wang et al. using the same simulation modules [6]. They just modeled the temperature of the component. In 2017, Khan et al. [7] examined the cooling times, total cycle times, volumetric shrinkage, and temperature variance of conventional, serial, parallel, and additive-parallel cooling channels. Despite the fact that there are many studies on CCC analysis, there are few studies on CCC design parameters for various types of designs. The designers used their past experience to implement the majority of the designs. According to the author's knowledge. Mixtures of any kind are extremely rare, as is consistency across design parameters, crosssection size, and experimental findings. Nonetheless, preliminary data from the literature was obtained, which will serve as a foundation for future research on this topic. Mayer [8] illustrates a basic relationship between four elements in the creation of CCCs using additive manufacturing. According to previous study, channel cross-sections other than circular could improve cooling efficiency. Cooling channels with variable spacing have been researched in extensively for tooling applications [9]. The authors conducted research in which they developed a complete method for conformal channel design in order to reconstruct an existing model that was originally built using straight channels using CCCs. Factors including duct diameter, pitch spacing, and wall to duct separation were considered by the writers.

This work compares the findings of a $3 D$ transient thermal research performed with two ANSYS packages: ANSYS Steady state/Transient Thermal in Workbench and ANSYS Mechanical APDL. The two modules packages are used for a variety of purposes: Workbench is more user-friendly and CAD-friendly. Mechanical APDL is fully integrated with ANSYS Parametric Design Language, ensuring that models developed there are fully parametrizable and compatible with any optimization approaches. The purpose of this study is to determine the appropriate meshing parameters for the best results. Both modules' outcomes are cross-validated at the same time. A similar work was already done in [10] 


\section{Background}

Injection molding is a popular advanced manufacturing technique for producing produced parts that is both cost-effective and dependable. The injection molding process consists of several steps [11]. The four steps are injection, packaging, cooling, and ejection: (1) injection, (2) packaging, (3) cooling, and (4) ejection. Injection molding is important in the plastics sector, accounting for a large percentage of total plastic usage [12]. Plastic injection molding is a versatile method for producing a wide range of complex sizes and shapes of high-quality items from thermoplastic and thermoset materials [13]. For generating a highquality plastic product, the injection mold design, particularly the design of the mold core and cavity, is crucial. It also has a big impact on the company's financial elements. Cooling channels must be employed to ensure temperature control and cooling of the molded component. Traditionally, cooling channels were bored straight using subtractive manufacturing techniques. CCCs might be made fast and cheaply using traditional processes. The shape of CCCs, on the other hand, has significant constraints that can slow down the injection molding process. Due to the geometry of the cavity, the necessity to avoid interference between the cavity and the channel, and the drilling procedure, straight drilled channels are impossible to produce perfect cooling. In this situation, only straight holes can be bored. Figure 1 shows a comparison of a straight cooling channel and a conformal cooling channel (left). CCC inserts are depicted in Fig. 1 right.
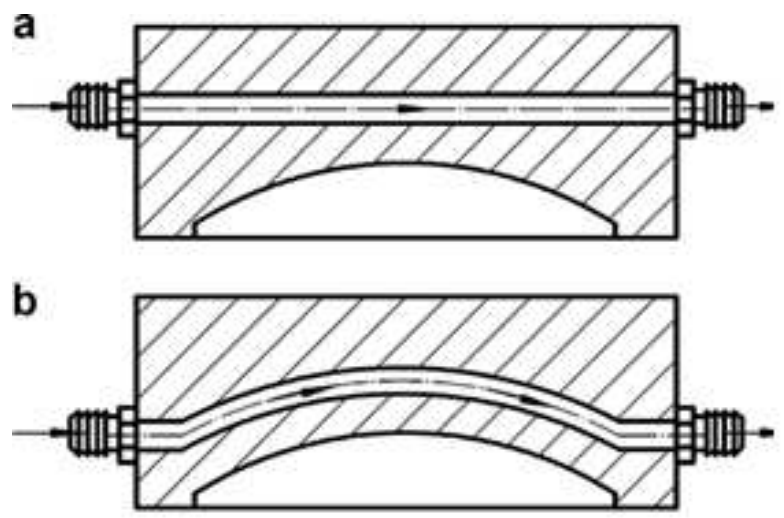

Fig. 3. Comparison of straight-drilled cooling channels and CC channels: straight-drilled cooling channels (a) and Conformal cooling channels (b), Adapted from [14], in [15])

When it comes to fabricating CCC shapes, traditional machining processes are frequently insufficient. As a result, they are made using additive manufacturing technologies [16-18] in [15]. As a result of recent developments in 3D printing technology, the CCC manufacturing approach has become more affordable and commercial. Injection molding is a method of heat transmission that is only 
temporary. It's safe to assume, though, that after a few injection molding cycles, it'll settle down (if the average mold temperature is considered constant). Heat transfer equilibrium is reached when the heat transfer rate (heat flux) from the molten polymer to the mold material matches the heat transfer rate (heat flux) from the mold material to the coolant and ambient air. Figure 2 depicts the heat movement in a simple manner.

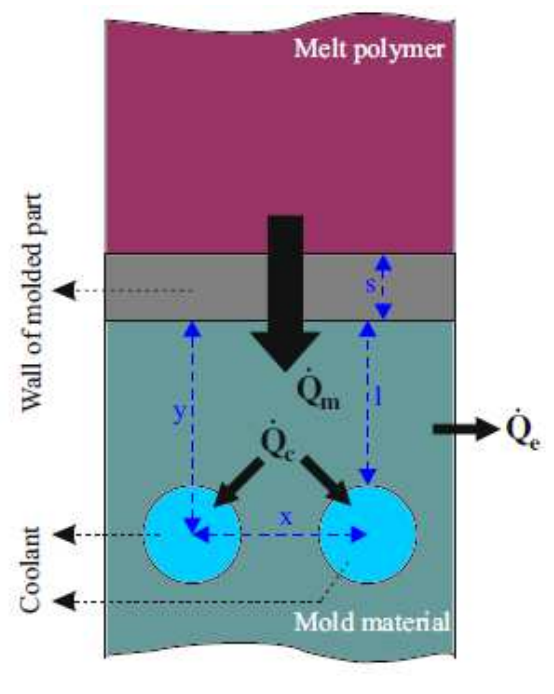

Fig. 2 - Simplified representation of the heat flows [19].

The balance equation is defined in Eq. 1 [20] in [19]

$$
\dot{Q}_{m}+\dot{Q}_{c}+\dot{Q}_{e}=0
$$

Conduction, convection, and radiation are the three basic heat transfer methods used in injection molding. The heat transmission rate (heat flux) from the molten polymer to the mold material, as well as the heat flux inside the mold material, is determined by the conductive heat transfer mechanism The heat flow from the mold material to the coolant is calculated using convective heat transfer. When the temperature of the mold material rises during the injection molding process, the surface temperature of the mold material rises above that of the ambient air. As a result, heat is transferred from the molding material to the surrounding air via both radiation and convection. Equations 2-4[21,22] define the conductive, convective, and radiative heat transfer rates analytically. 


$$
\begin{aligned}
& \dot{Q}_{\text {cond }}=\int_{0}^{t_{\text {cocle }}} \frac{\lambda}{\delta} \cdot A \cdot \Delta T \cdot d t \\
& \dot{Q}_{\text {conv }}=\int_{0}^{t_{\text {cocle }}} \alpha \cdot A \cdot \Delta T \cdot d t \\
& \dot{Q}_{\text {rad }}=\int_{0}^{t_{\text {ovcle }}} \sigma_{0} \cdot \varepsilon \cdot A \cdot \Delta T^{4} \cdot d t
\end{aligned}
$$

In Eq. 2, and are the thermal conductivity and thickness, respectively, in Eq. 3, and 0 and are the constant Stefan-Boltzmann and emissivity, respectively, in Eq. 4. T and A stand for temperature and cross-sectional area, respectively. In order to improve the cooling performance of CCCs, maximization is commonly pursued during the cooling process. The smallest value of implies heat loss over the molding material boundary, while the biggest value of denotes the smallest value of. In other circumstances, the obtained loss is less than $5 \%$. As a result, $Q_{e}$ is regarded as negligible, and the molding material boundary is assumed to be adiabatic [23,24].

When the $\dot{Q}_{e}$ is neglected, Eq. 1 can be rewritten as Eq. 5 [19]:

$$
\dot{Q}_{m}+\dot{Q}_{c}=0
$$

Rao et al [25] defines $\dot{Q}_{m}$ as in Eq. 6,

$$
\dot{Q}_{m}=10^{-3} \cdot\left[\left(T_{p}-T_{e}\right) \cdot C_{p}+i_{p}\right] \cdot \rho_{p} \cdot \frac{s}{2} \cdot x
$$

where $\mathrm{Tp}$ and Te are the polymer melt and demolding temperatures, $\mathrm{cp}$ is the polymer's specific heat, ip is the latent heat, $p$ is the polymer melt density, $s$ is the molded component thickness, and $\mathrm{x}$ is the cooling channel pitch difference. Furthermore, Eq. 7 [19] states:

$$
\dot{Q}_{c}=10^{-3} \cdot t_{k} \cdot\left(\frac{1}{\lambda_{m} \cdot S h}+\frac{1}{\alpha \cdot 10^{-3} \cdot d \cdot \pi}\right)^{-1} \cdot\left(T_{m w}-T_{c}\right)
$$

where tk is the cooling time, $\mathrm{m}$ is the thermal conductivity of the tool material, Sh is the form factor of the cooling channel geometry, $d$ is the cooling channel diameter, Tmw is the tool material's wall temperature, and Tc is the coolant's supplied temperature 
All of the prameters in equations 6 and 7 are known or assumed during the operation, with the exception of the values tk and Tmw [19]. Without taking into account the effect of axial conduction, [26] can be used to express the energy equation:

$$
\rho c_{p} V_{z} \frac{\partial T}{\partial z}=k \frac{1}{r} \frac{\partial}{\partial r}\left(r \frac{\partial T}{\partial r}\right)+\mu\left(\frac{\partial V_{z}}{\partial r}\right)^{2}
$$

The phenomena of heat transmission at the interface between the mold cavity and the molten polymer is complex. There are several factors to consider, including surface roughness, geometry, mold coating, and polymer composition. The most commonly cited criterion for the contact heat transfer rate is that the heat flux must be maintained across the discontinuity [27]:

$$
q^{\|}=h\left(T_{\text {melt }}-T_{\text {mould }}\right)
$$

The thermal contact resistance coefficient, $h$, is calculated experimentally [27]. After determining temperature and velocity profiles for any z-axis position, the average melt temperature can be calculated using the mixing cup temperature idea [29]. The associated equation is as follows:

$$
T_{\text {avg }}=\frac{\int_{0}^{R} \rho \cdot 2 \cdot \pi \cdot r \cdot d r \cdot V_{z} \cdot c_{p} \cdot T}{\int_{0}^{R} \rho \cdot 2 \cdot \eta \cdot r \cdot d r \cdot V_{z} \cdot c_{p}}
$$

Theoretical considerations of heat transport are critical in injection molding. An important equation is the energy balance. energy balance can be written using Equation 11 [29]:

$$
\rho_{m} C_{m} l_{m} \frac{d T_{m}}{d t}+\frac{h \pi D K_{m}}{2 K_{m} W+h \pi D l_{m}}=\frac{\rho_{p} C_{p} l_{p}\left(T_{\text {melt }}-T_{\text {eject }}\right)}{t_{\text {cycle }}}
$$

The tool's active component is the area between the surface and the cooling lines. The first term in equation represents the tool's thermal mass and the build-up of heat as the tool temperature rises (18). The second part in equation represents heat transmission through conduction through the tool and then convection into the coolant (18). The right-hand side of the equation represents the heat source (18). The heat source is assumed to be the cooling of the plastic. A first-order ordinary differential equation having a solution in the form of equation (12) [29] is represented by equation (11).

$$
T_{m}(t)=T_{m 0}+\left(T_{m s}-T_{m 0}\right) e^{\frac{-t}{\tau}}
$$


where Tms is the system's time constant and is the steady-state cycle-averaged tool temperature.

Equations (13) and (14) represent the cycle-averaged tool temperature and time constant, respectively. Conformal cooling (CC) is now formally defined as being smaller than or equal to the injection cycle time [29]:

$$
\begin{aligned}
& T_{m s}=T_{c}+\frac{\rho_{p} C_{p} l_{p}\left(2 K_{m} W+h \pi D l_{m}\right)\left(T_{m e l t}-T_{\text {eject }}\right)}{h \pi D K_{m} t_{c y c l e}} \\
& \tau=\frac{\rho^{m} C^{m} l_{m}\left(h \pi D l_{m}+2 K^{m} W\right)}{h \pi D K^{m}}
\end{aligned}
$$

The expression for the time constant in equation (14) [29] is reduced to the form provided in equation (15) when heat transport is considered to be lossless:

$$
\tau=\frac{\rho_{m} C_{m} l_{m}^{2}}{K_{m}}
$$

Equation 15 considers the case where the heat transfer coefficient is infinite, which is the same as supposing that heat transport to the molten liquid is $100 \%$ efficient [29].

\section{Procedure}

\subsection{Geometry and sets}

The geometry of the analyzed 3D model is presented in Figure 3. All the dimensions were scaled to half of the original mold [30-32], due to the need of reducing the computation power required to solve the numerical analyses. 

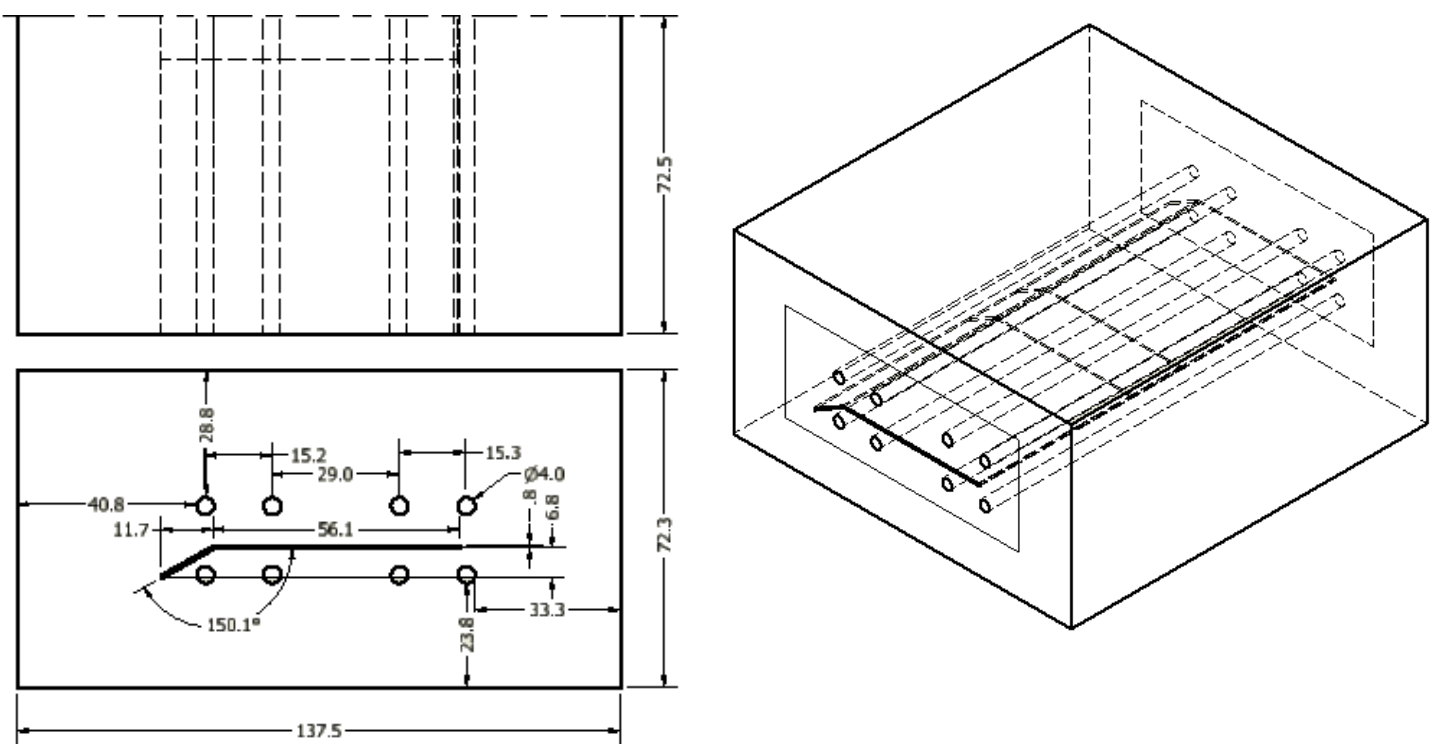

Fig. 3-Set drawing: simplification of the 3D model, also presented in [33,34]

The components of the geometry (Fig. 1), are shown in Fig. 4.

10

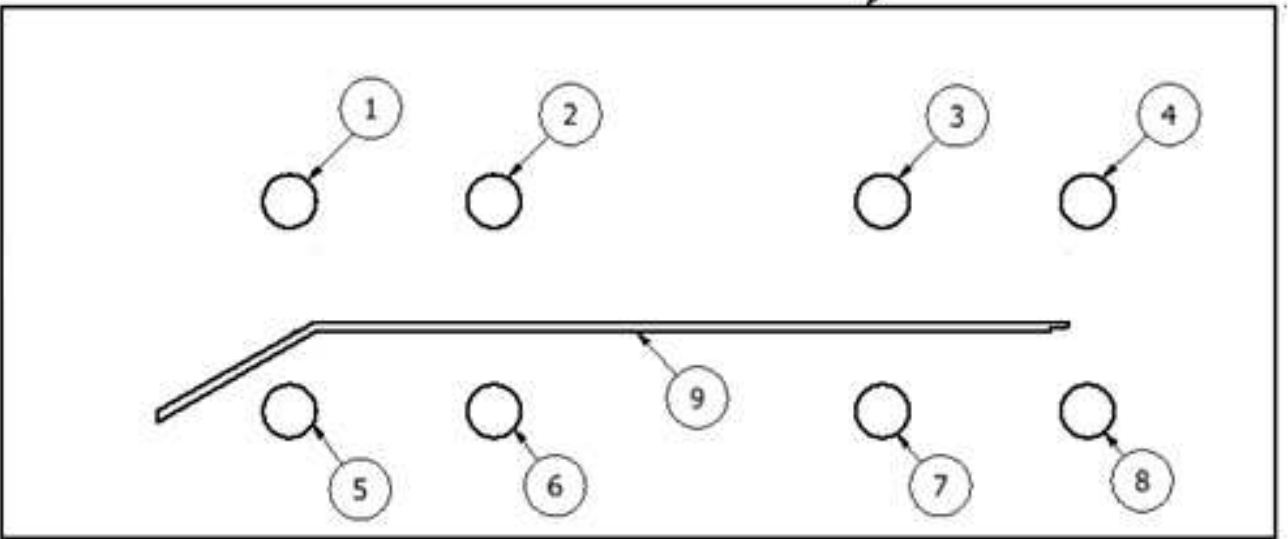

Fig. 4. - Components of the assembly, represented by numbers from 1 to 10 The components of the geometry are explained in Table 1:

Table 1-Components of the geometry used in the simulations

\begin{tabular}{|c|c|c|}
\hline $\begin{array}{c}\text { Component } \\
\text { ID }\end{array}$ & Quantity & Description \\
\hline 1 & 1 & Part \\
\hline 2 & 8 & Channels \\
\hline 3 & 1 & Mold \\
\hline
\end{tabular}

Water in the liquid phase was used for the cooling channels, which are represented by circles and numbered from (1) to (8) in Fig. 4. The injected component is polypropylene (PP), while the mold cavity is considered to be made of p20 steel. 


\subsection{Materials}

In the simulations, performed in ANSYS Mechanical APDL 2020 R2, water was used for the cooling channels and PP was used for the injected component. P20 steel was utilized for the mold. Only water is considered as a fluid; PP and steel, on the other hand, are regarded to be solid. The properties of the materials used are listed in Table 2.

Table 2 - Properties of water, PP and P20 steel [30-34].

\begin{tabular}{|l|l|l|l|}
\hline Material & $\begin{array}{l}\text { Water in } \\
\text { liquid state }\end{array}$ & $\begin{array}{l}\text { Polypropylene, } \\
\text { with } 10 \% \text { mineral }\end{array}$ & P20 steel \\
\hline Density $\left[\left(\mathrm{kg} / \mathrm{m}^{\wedge} 3\right)\right]$ & 998.2 & 1050 & 7861 \\
\hline $\begin{array}{l}\text { Specific heat }[\mathrm{J} / \\
\text { (kg.K)] }\end{array}$ & 4182 & $\begin{array}{l}1800, \text { Considered } \\
\text { constant }\end{array}$ & 502,48 \\
\hline $\begin{array}{l}\text { Thermal conductivity } \\
{[\mathrm{W} /(\mathrm{mK})]}\end{array}$ & 0.6 & $\begin{array}{l}0.2 \text { Considered } \\
\text { constant }\end{array}$ & 41,5 \\
\hline
\end{tabular}

\subsection{Numerical procedure}

The meshing parameters are shown in Table 3.

Table 3 - Meshing parameters

\begin{tabular}{|l|l|l|}
\hline & Esize $[\mathrm{mm}]$ & Mesh type \\
\hline Cooling channels and mold & 2.5 & $\begin{array}{l}\text { Quadrilateral free } \\
\text { mesh }\end{array}$ \\
\hline Part & 0.07 & m \\
\hline
\end{tabular}

Both modules employed the identical mesh parameters. Fig 5 top and bottom show the mesh in Mechanical APDL and Workbench, respectively. 
a)

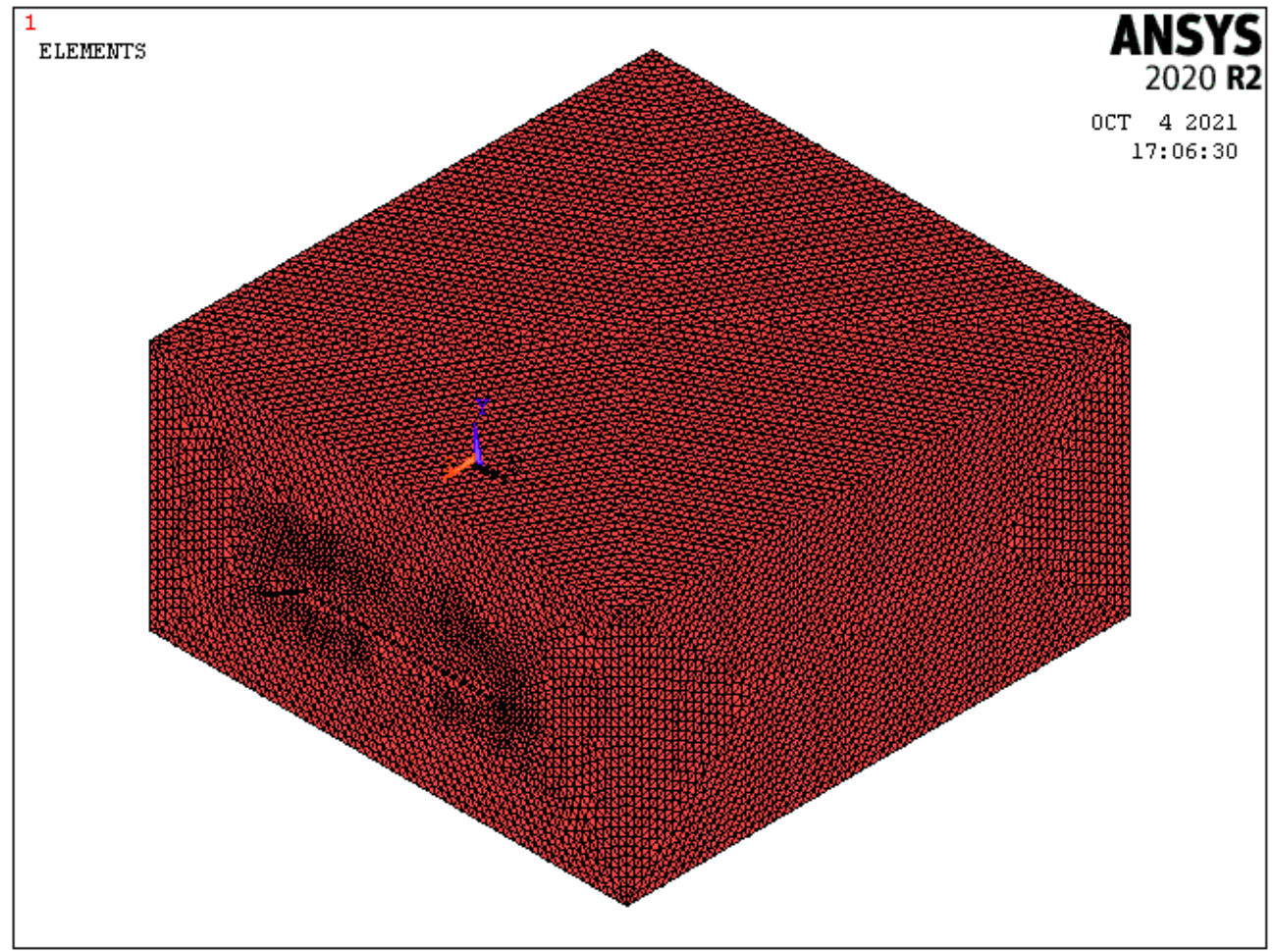

b)

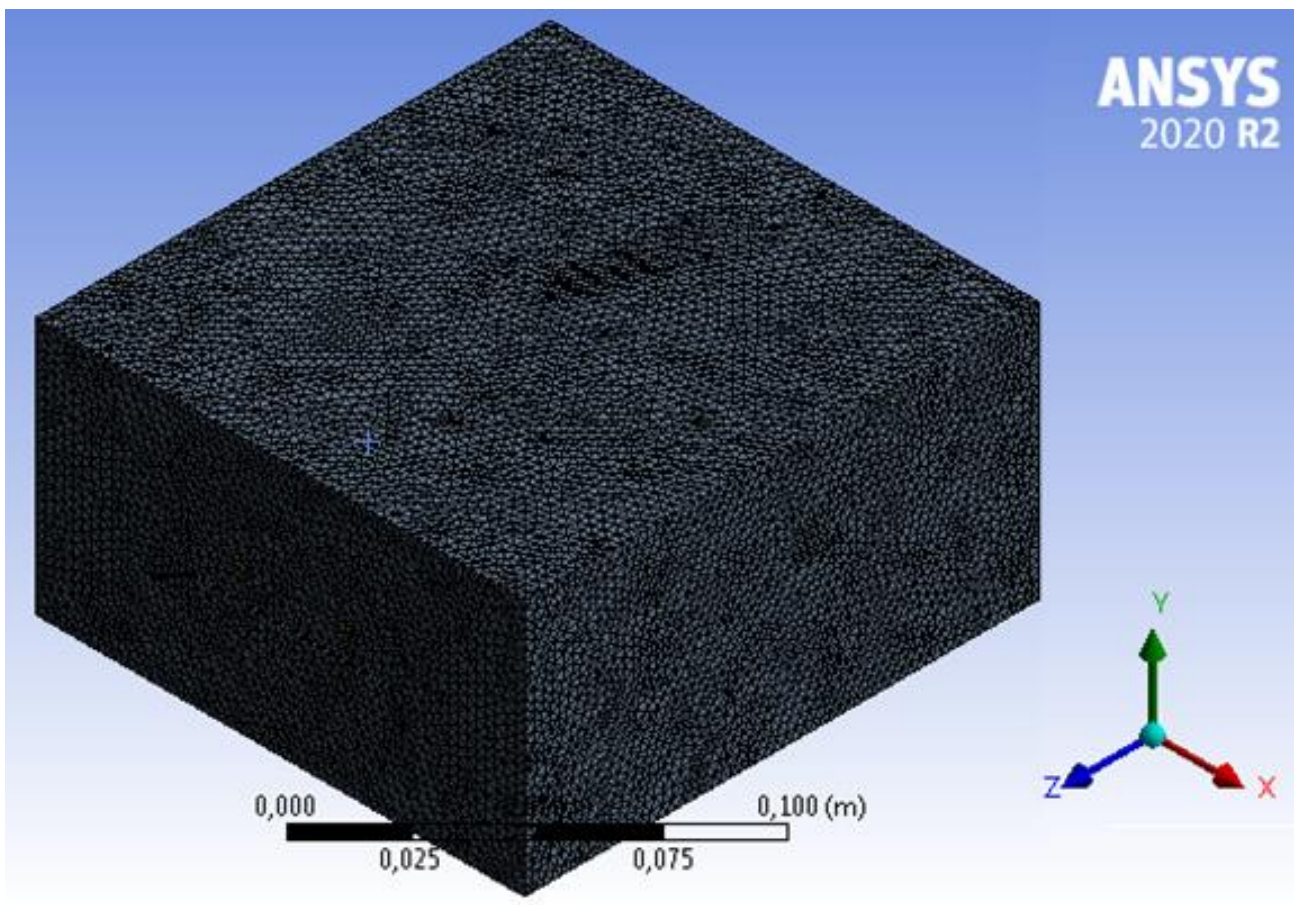

Fig.5 - Mesh in ANSYS Mechanical APDL (a) and in ANSYS Workbench (b) 
The boundary conditions implemented in ANSYS Mechanical APDL 2020 r2 are listed in Table 4.

Table 4 - Thermal conditions applied [30-34]

\begin{tabular}{|l|l|l|}
\hline Condition & Value [C] & Application \\
\hline Tini & 210 & $\begin{array}{l}\text { Part, 1 volume, component } \\
(9)\end{array}$ \\
\hline Tini & 40 & $\begin{array}{l}\text { Cooling channels, 8 } \\
\text { volumes, components (1) to } \\
(8)\end{array}$ \\
\hline T & 40 & $\begin{array}{l}\text { Mold, 1 volume, represented } \\
\text { by (10) }\end{array}$ \\
\hline T & 23 & $\begin{array}{l}\text { Boundary, outer areas of } \\
(10) \text { (Total of 6 areas) }\end{array}$ \\
\hline
\end{tabular}

The temperature of $210[\mathrm{C}]$ is an approximation of the processing temperature of PP. It is assumed that the water in the cooling channels is at a constant temperature of $40[\mathrm{C}]$. The methodology used in this study was to compare and validate numerical findings using two different software modules from the same suite, in this case, ANSYS. A flowchart depicting the process is shown in Figure 6.

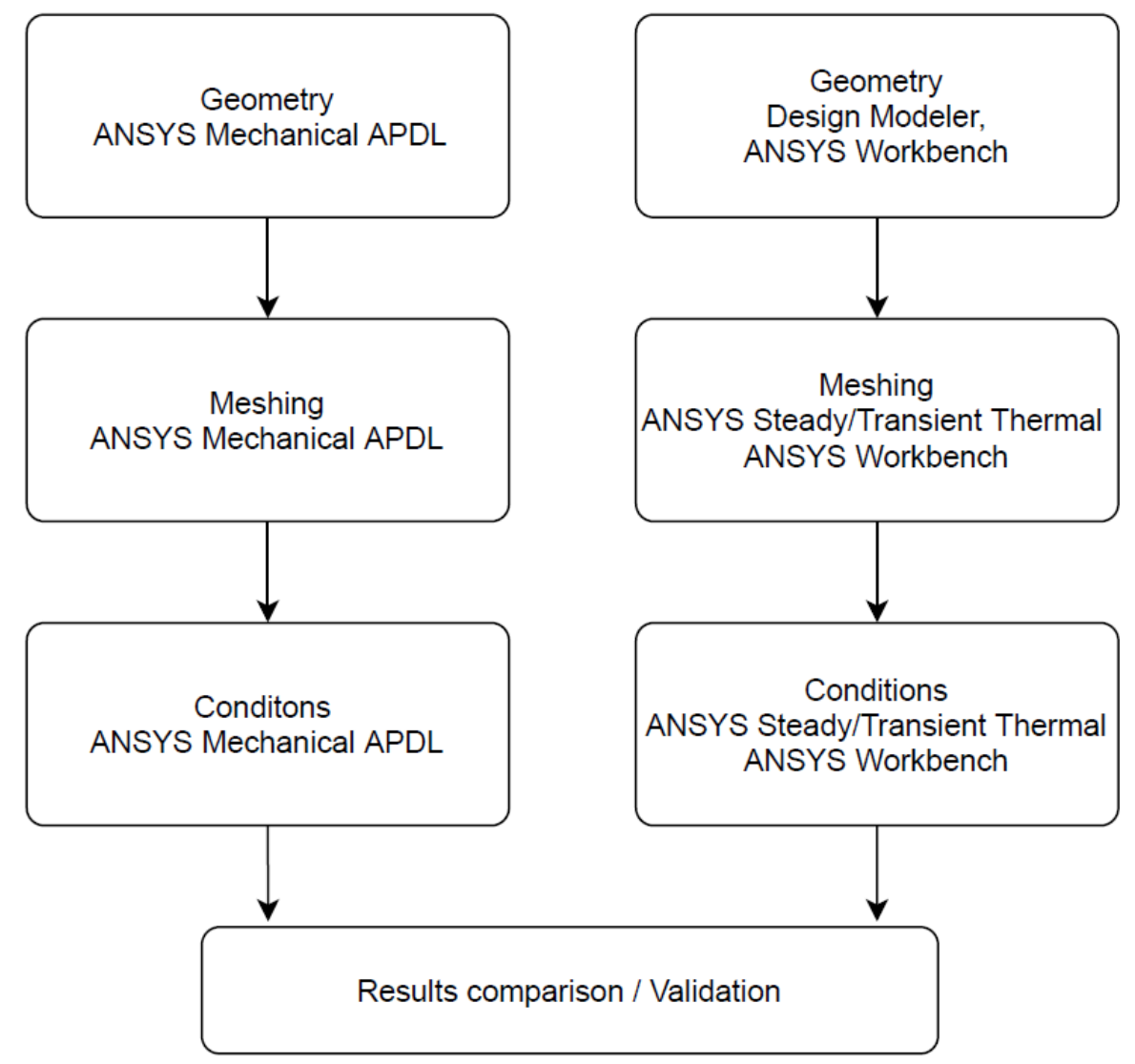

Fig. 6 -Methodology developed for the validation of the numerical results. 
Geometry construction, meshing, specifying beginning and boundary conditions, and solution are all standard phase in a Finite Element analysis. However, there are two major distinctions between the two approaches: in both modules, the geometry was constructed natively, implying that the geometry environment is different. Another distinction is due to the meshing. Different meshing results from the same mesh settings, with considerable variances in the number of components. This could be because Workbench meshing has a lot more meshing choices than Mechanical APDL. In all settings that are present in Workbench but not in Mechanical APDL, the default value was retained.

\section{Results and Discussion}

4. Results

\subsection{Contours}

The aim of this work is to get the temperature distribution for the time where the temperature is lower than the ejection temperature of $70 \mathrm{C}$. Considering time steps of $0.5 \mathrm{~s}$ in the simulation, for $\mathrm{t}=2 \mathrm{~s}$, the first global results whose maximum temperature is lower than $70 \mathrm{C}$, are obtained. Contours were, therefore, obtained for t from 0 to $2 \mathrm{~s}$ with steps of $0.5 \mathrm{~s}$. These are shown in Fig.7-10

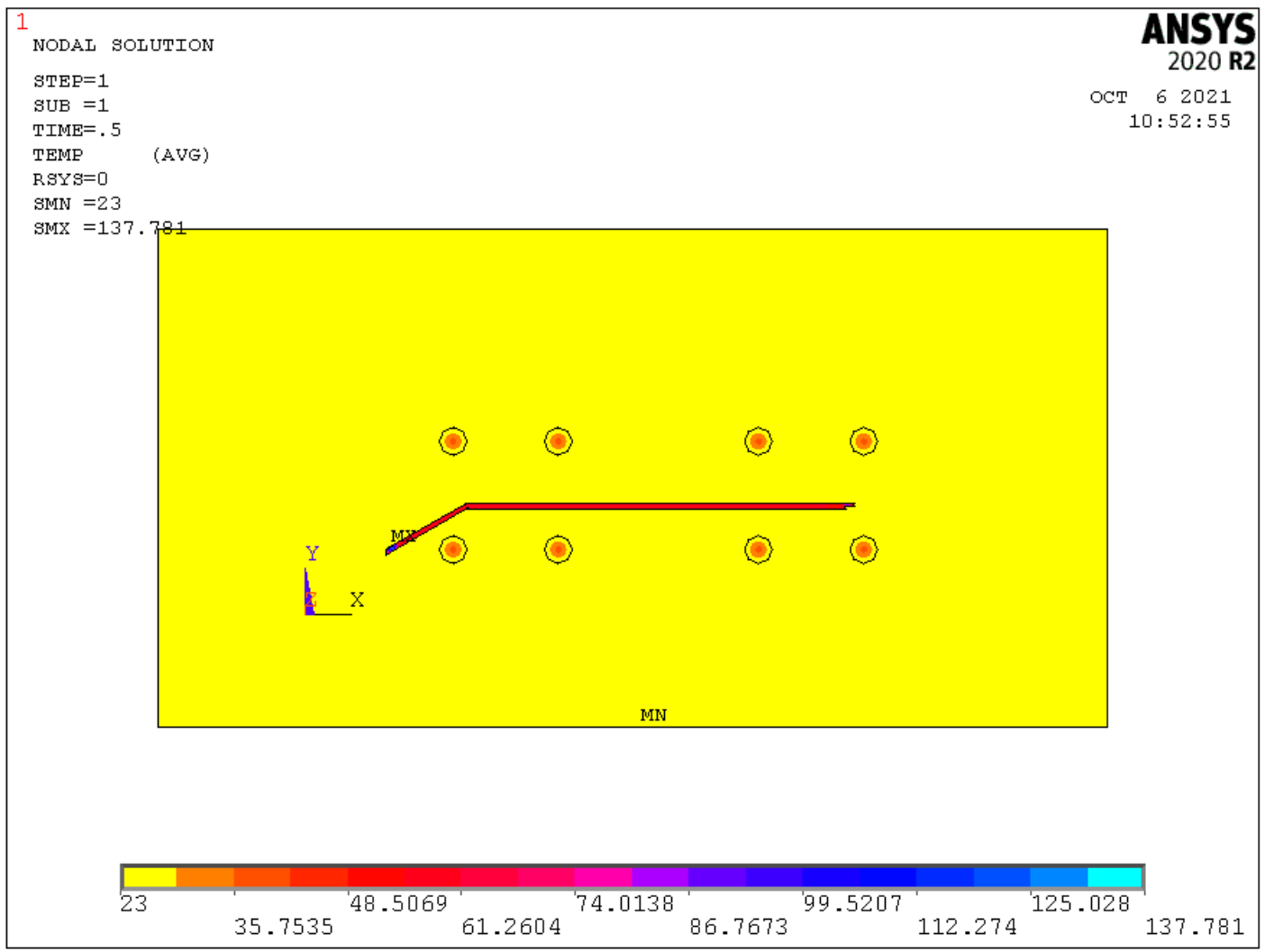


b)

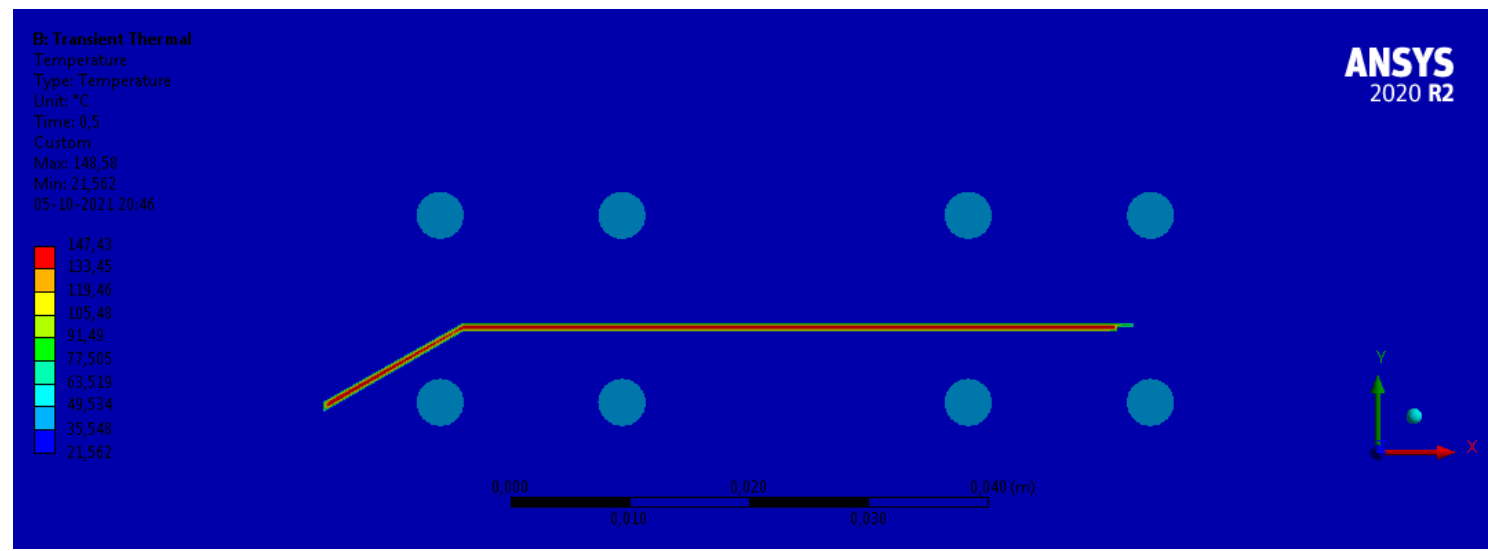

Fig.7 - Temperature contours for both ANSYS APDL (a) and Workbench (b), $\mathrm{t}=0.5 \mathrm{~s}$

a)

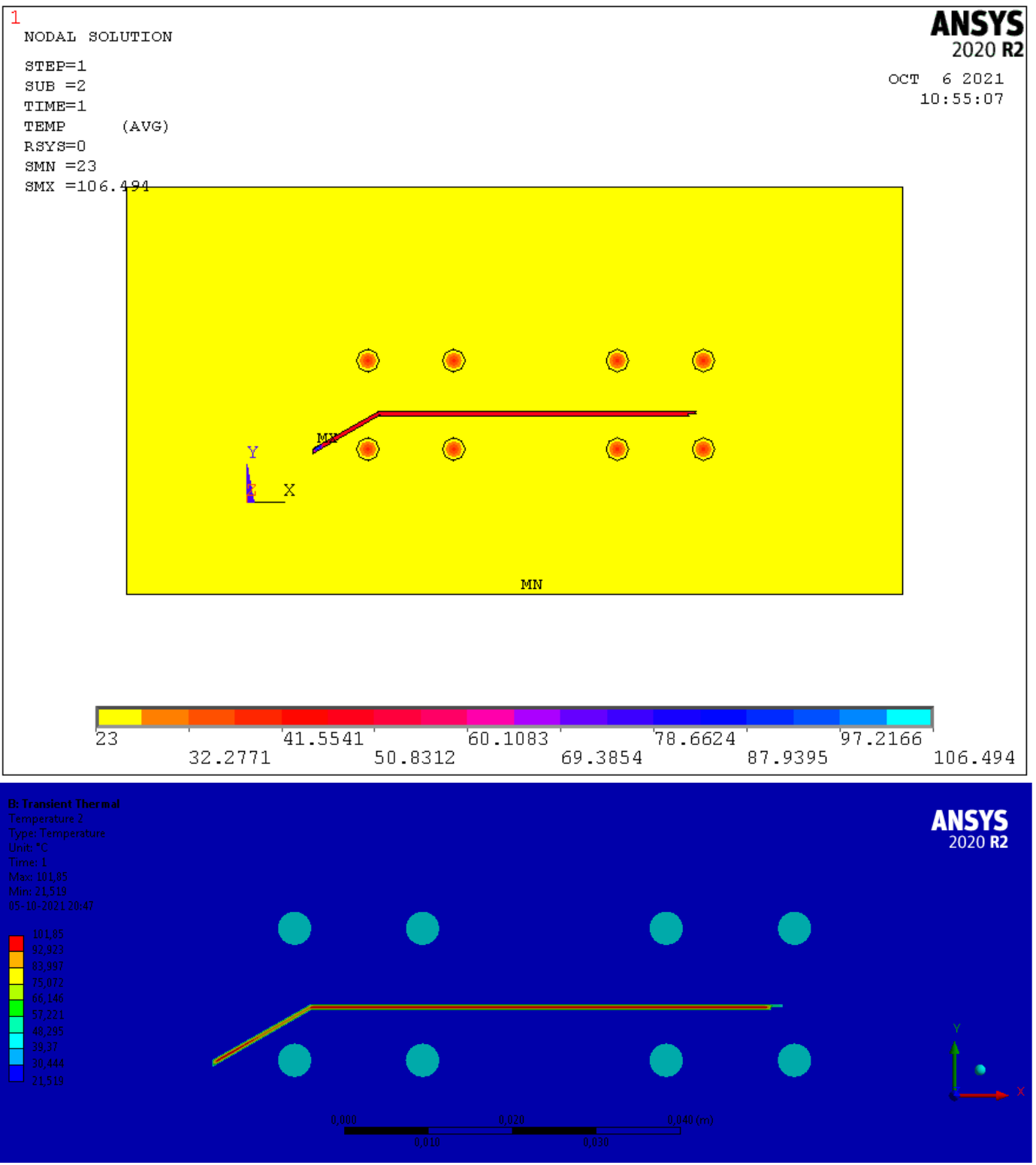

Fig.8 - Temperature contours for both ANSYS APDL (a) and Workbench (b), $\mathrm{t}=1 \mathrm{~s}$ 
a)

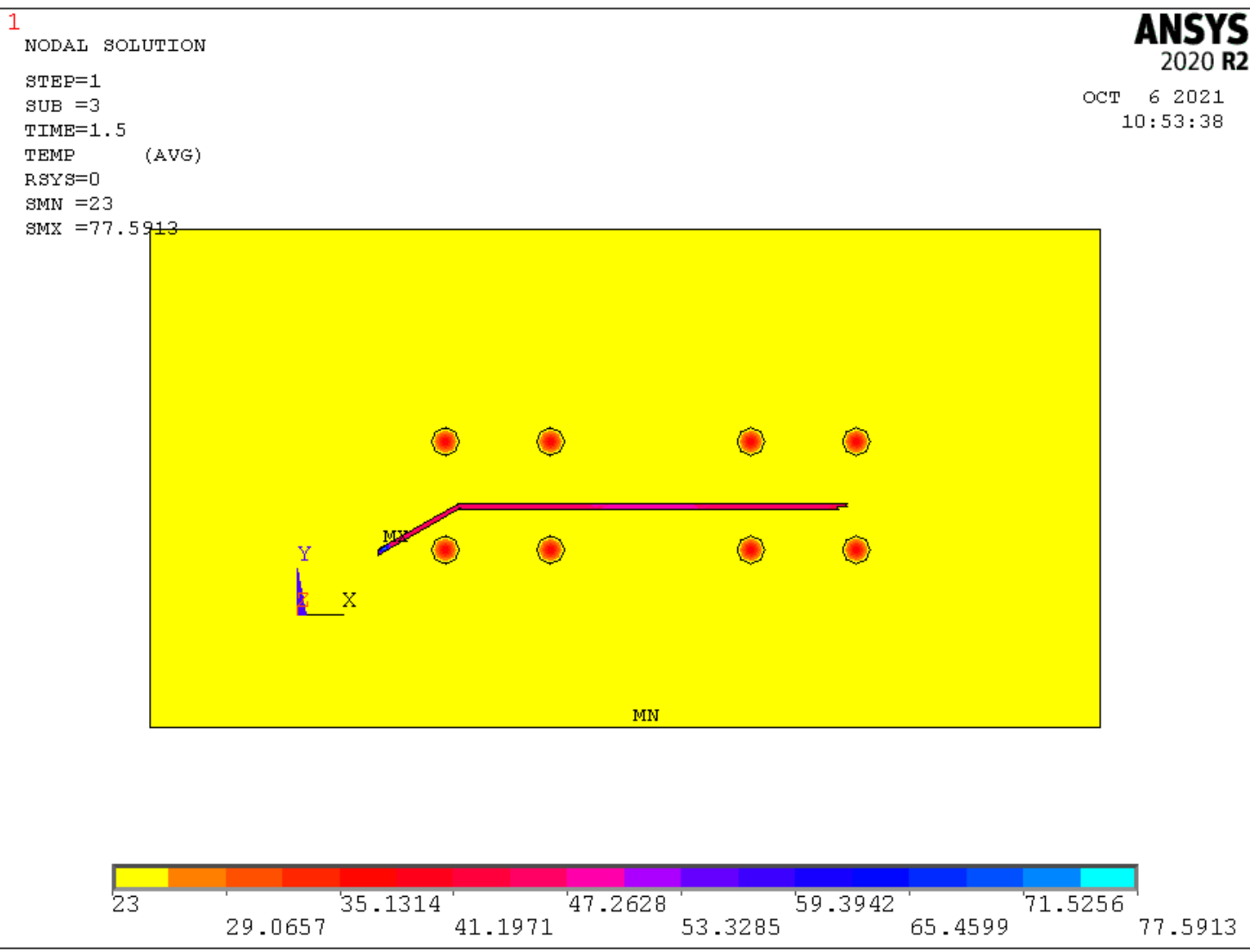

b)

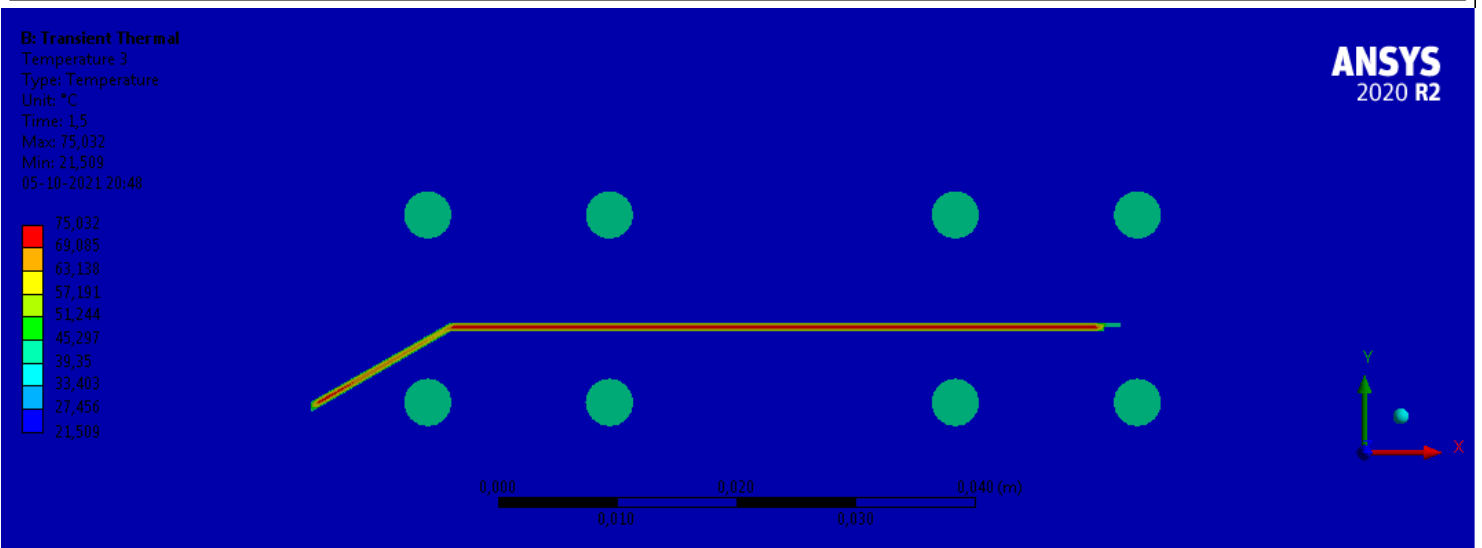

Fig. 9- Temperature contours for both ANSYS APDL (a) and Workbench (b), $\mathrm{t}=1.5 \mathrm{~s}$ 


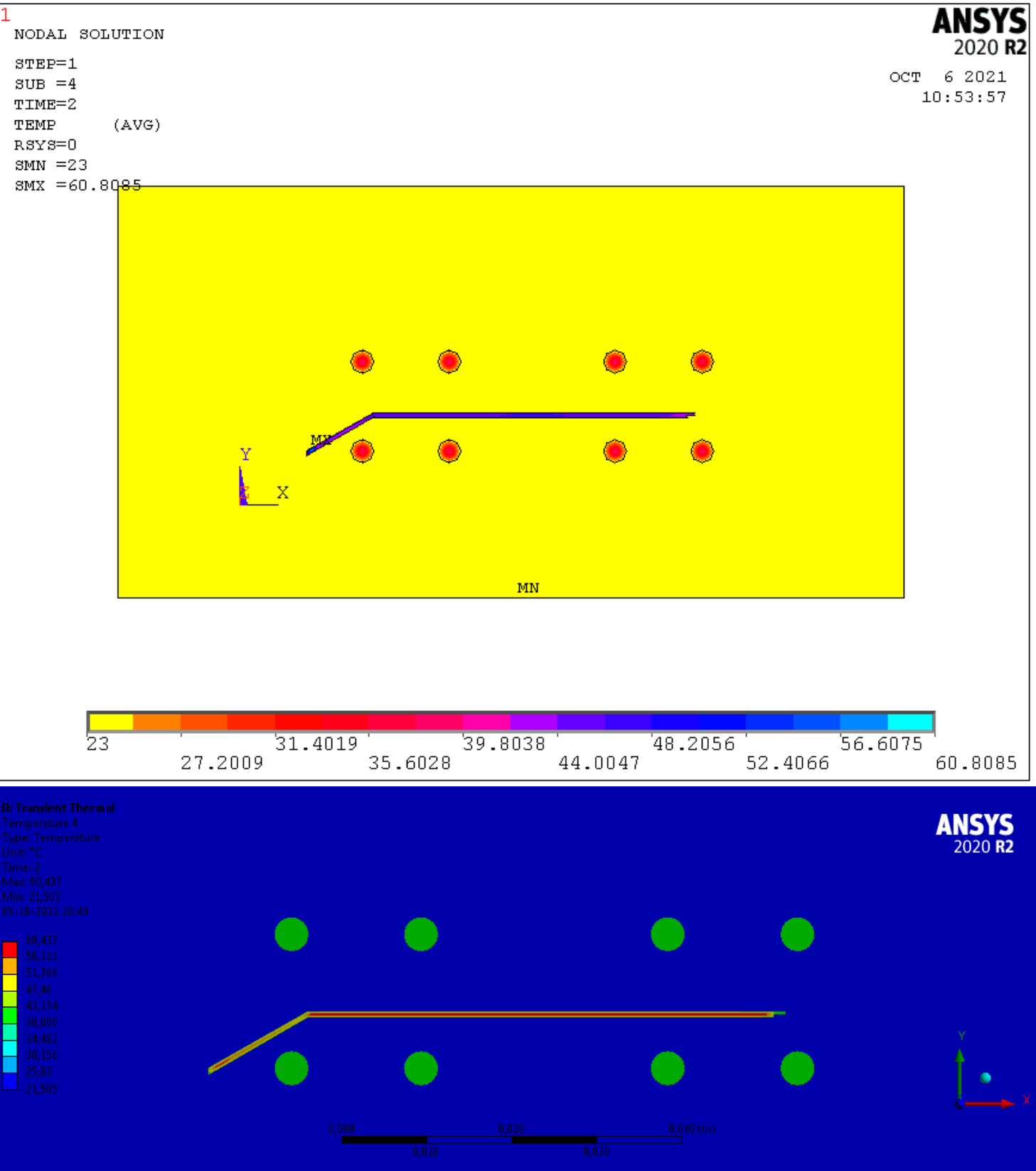

Fig.10 - Temperature contours for both ANSYS APDL (a) and Workbench (b), $\mathrm{t}=2 \mathrm{~s}$

\subsection{Comparison}

Fig. 11 shows the maximum temperature Tmax in function of time, for both Mechanical APDL and Workbench. 


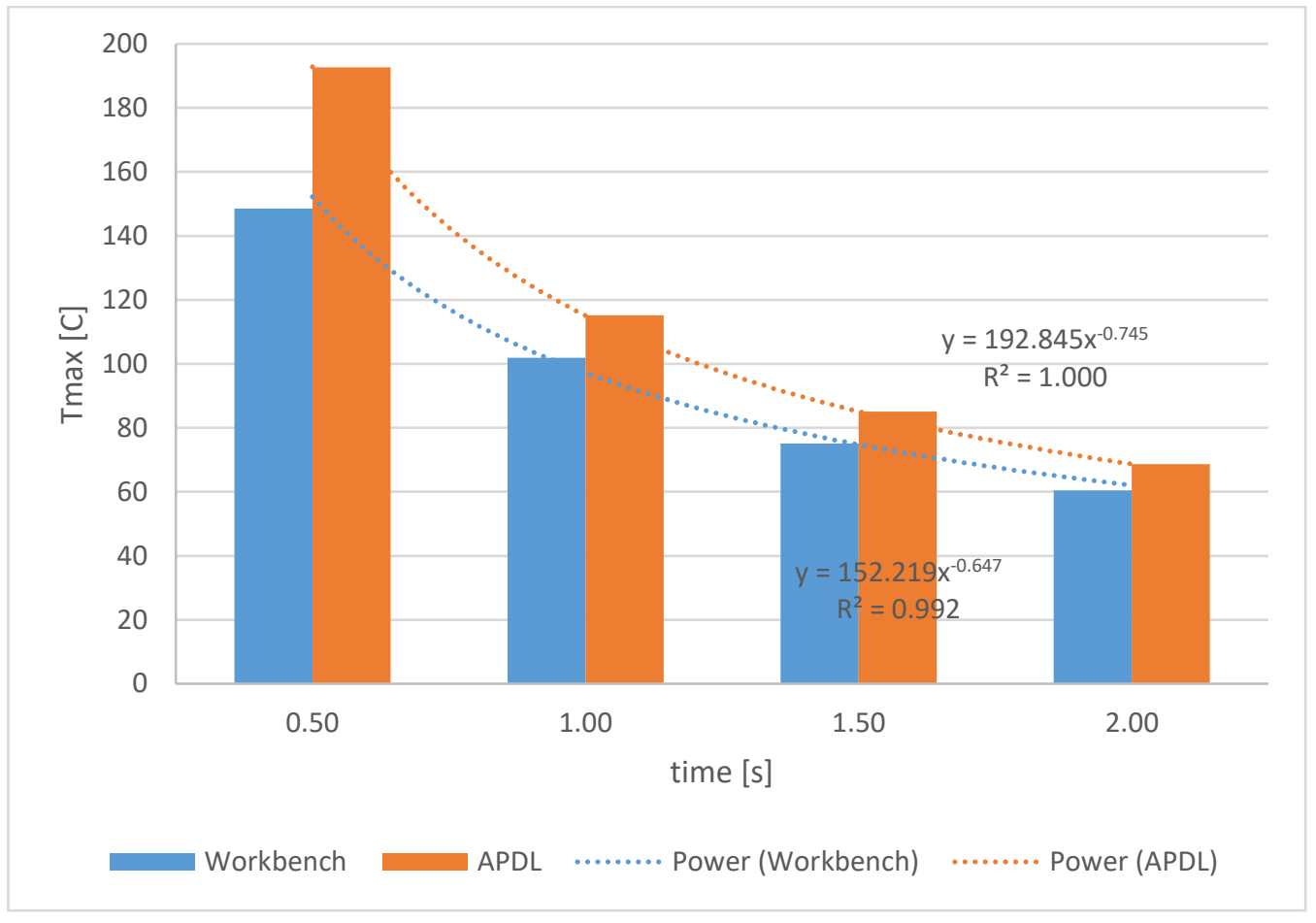

Fig. 11-Maximum temperature in function of time, for both Mechanical APDL and Workbench

One can see in Fig. 11 that results by Workbench are very close to those of Mechanical APDL. In most cases, workbench show values of maximum temperature slightly higher than APDL. Fig. 12 shows the average temperature Tavg in function of time, for both Mechanical APDL and Workbench.

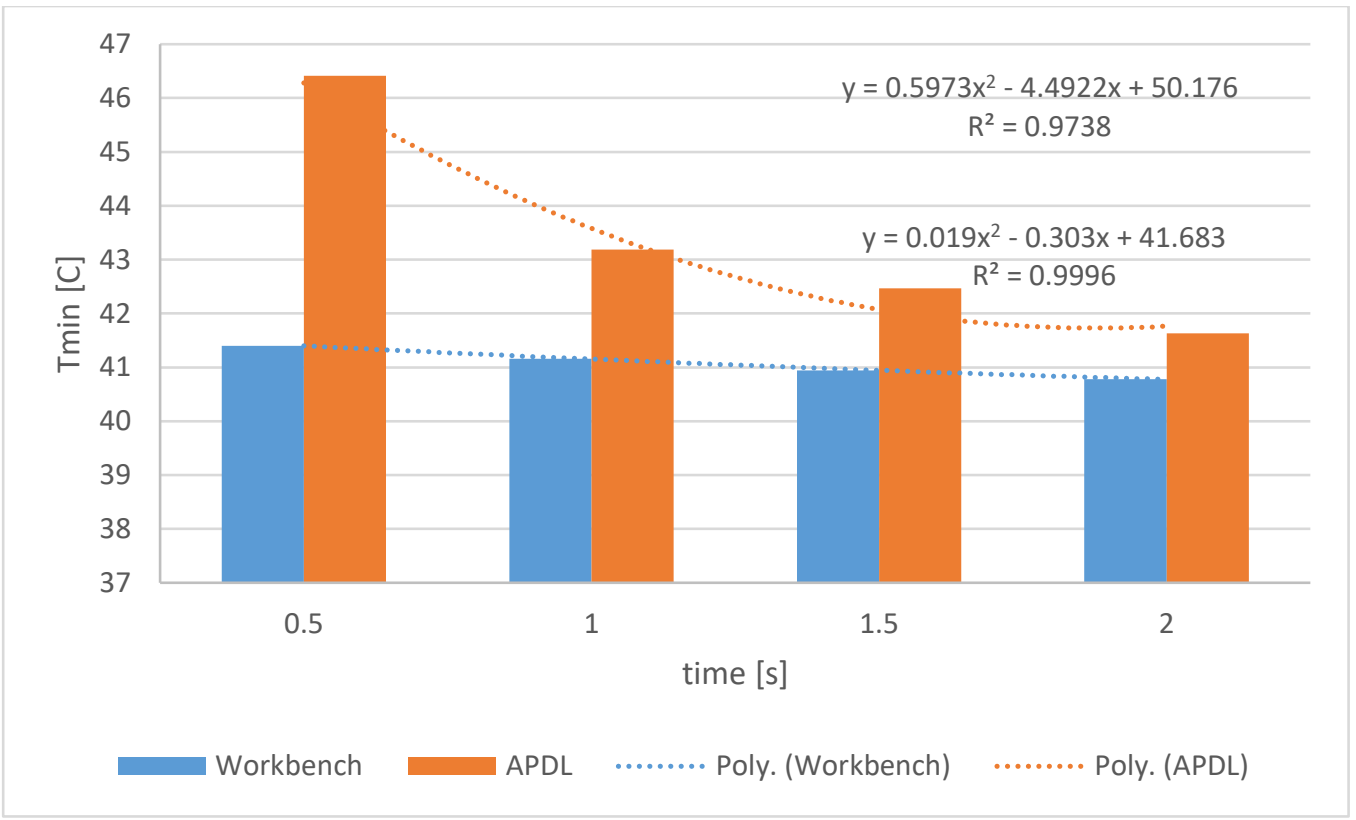

Fig. 12 -Minimum temperature in function of time, for both Mechanical APDL and Workbench

It can be seen in Fig. 12 that Mechanical APDL presents a higher value than Workbench for the majority of the cases. However, the differences between both 
software modules decrease along time. Fig. 13 presents the average temperatures vs time.

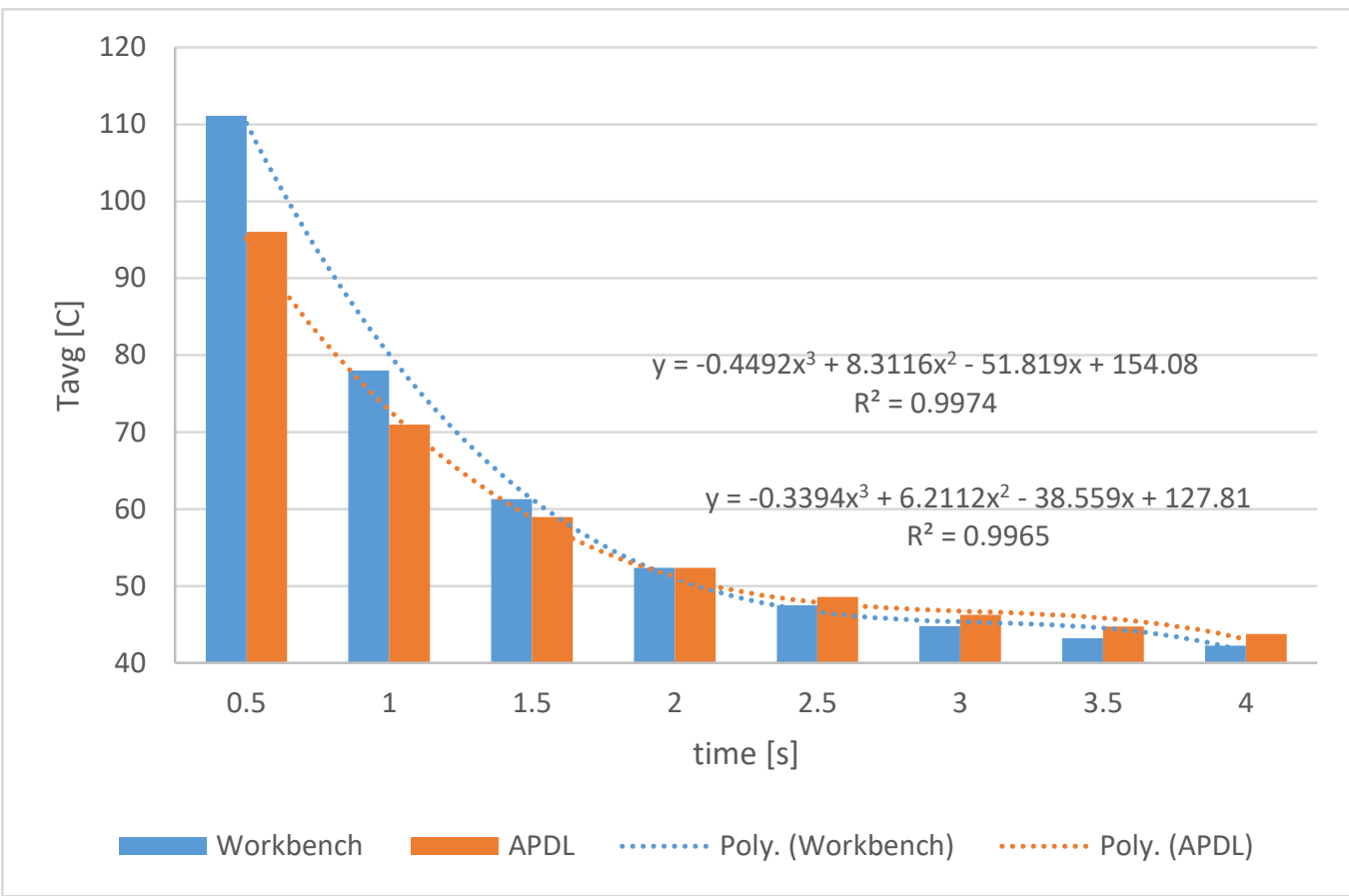

Fig. 13 -Average temperature in function of time, for both Mechanical APDL and Workbench

The errors regarding the results shown in Fig. 13 (Tavg) are shown in Fig. 14. The errors were calculated using (16)

$$
\mid \text { Error }_{[\%]}=\frac{\left|T_{w b}-T_{A P D L}\right|}{T_{w b}} * 100 \%
$$

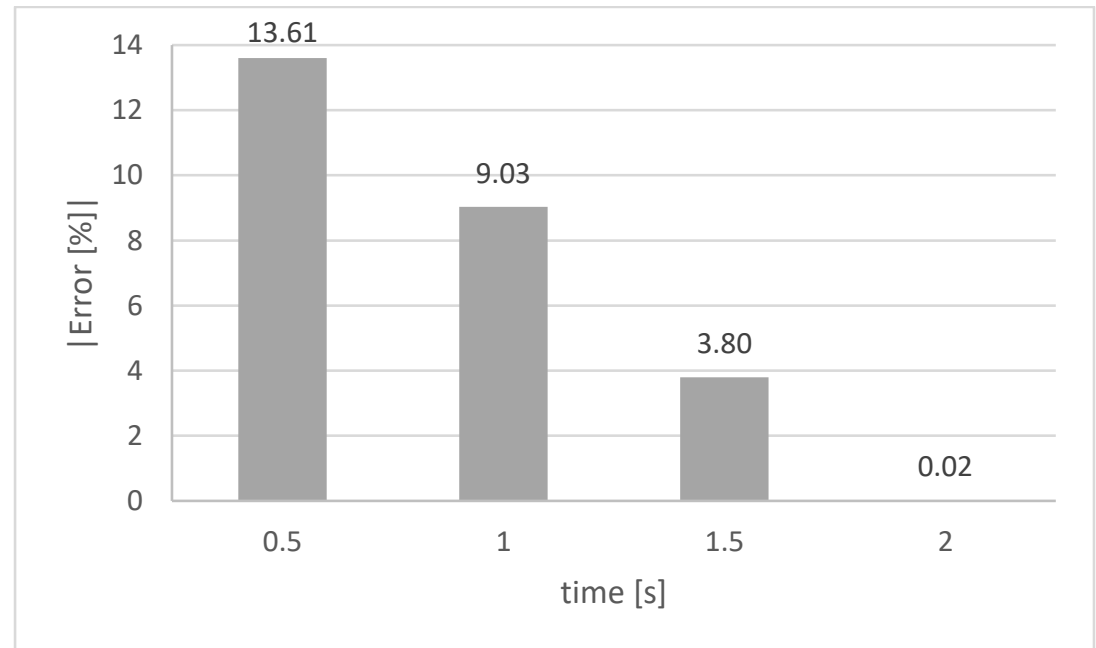

Fig. 14- Error between Mechanical APDL and Workbench, in function of time, for average temperature

As it is shown in Fig. 14, the error in function of time fits an exponential function, in the case of the average temperature Tavg and a $3^{\text {rd }}$ degree polynomial function, in the case of the maximum temperature Tmax. The value of the 
quadratic correlation is very close to 1, as is shown in Fig. 13. The temperature distribution shows some differences in the two software modules for all the studied substeps, shown in Figs. 11 and 12. However, it is possible to conclude that the values of the temperature are close in both ANSYS Mechanical APDL and ANSYS Workbench. The contours show some difference in the color distribution, as a characteristic of the assumptions of the software modules. It is possible to see that for $t=2 s$ the temperature distribution shows a better agreement than for $t=4 \mathrm{~s}$ and $\mathrm{t}=2 \mathrm{~s}$. This is also shown in Fig. 13, for the maximum and average values of the temperature

\section{Conclusions}

It may be determined that, for the condition under consideration, a mesh of 0.07 $\mathrm{mm}$ is fine enough to obtain satisfactory precision. Analytical models for temperature prediction over time, totaling four, were obtained in the form of 2nd degree quadratic equations, as shown in Figs. 11 and 12. Despite best attempts, there are some changes in module settings between the two programs employed, limiting the goal of duplicating exact simulation conditions, particularly in terms of meshing properties. In fact, element type and mesh details were shown to be the most significant distinctions. Because of this, there may be a divergence between the two modules for coarse meshes, whereas a good agreement is established for the most refined mesh. As a result, the variances in characteristics of the meshing modules in the two software packages, mainly in what relates to the elements specifically and to the mesh, in general, are the primary causes of the observed numerical discrepancies In the future, the errors between the two software packages might be fit into two alternative equations. These equations can be used to determine whether additional mesh refining is worth the extra computational work.

\section{Declarations}

\section{a. Funding}

This research was supported by the Research Grant number POCl-01-0247FEDER-024516, co-funded by the European Regional Development Fund, by the Operational Programme "Competitiveness and Internationalization", in the scope of "Portugal 2020"

\section{b. Conflicts of interest/Competing interests}

There are no declared Conflicts of interest/Competing interests 


\section{Availability of data and material (data transparency)}

The datasets generated during and/or analysed during the current study are available from the corresponding author on reasonable request.

\section{d. Code availability}

Not applicable

\section{e. Ethics approval}

Not applicable

\section{f. Consent to participate}

Not applicable

\section{g. Consent for publication}

Not applicable

\section{References}

[1] Dimla D, Camilotto M , Miani F (2005). Design and optimisation of conformal cooling channels in injection molding tools. Journal of Materials Processing Technology, 164, 1294-1300.

[2] Saifullah A., Masood S. (2007) Finite element thermal analysis of conformal cooling channels in injection molding. Proceedings of the 5th Australasian congress on applied mechanics.

[3] Saifullah A., Masood S , Sbarski I (2009) New cooling channel design for injection molding. Proceedings of the World Congress on Engineering.

[4] Gloinn T Ó, Hayes C, Hanniffy P, Vaugh K. (2007). FEA simulation of conformal cooling within injection molds. International Journal of Manufacturing Research, 2, 162-170. 
[5] Au K, Yu K (2007). A scaffolding architecture for conformal cooling design in rapid plastic injection molding. The International Journal of Advanced Manufacturing Technology, 34, 496-515.

[6] Wang Y, Yu K M, Wang C C, Zhang, Y. (2011). Automatic design of conformal cooling circuits for rapid tooling. Computer-Aided Design, 43, 1001-1010.

[7] Khan M, Afaq S K, Khan N U , Ahmad S (2014). Cycle Time Reduction in Injection Molding Process by Selection of Robust Cooling Channel Design. International Scholarly Research Notices, 2014.

[8] Mayer, S (2005). Optimised mold temperature control procedure using DMLS. EOS Whitepaper, EOS, GmbH Ltd, 1-10.

[9] Au K, Yu K. (2014) Variable distance adjustment for conformal cooling channel design in rapid tool," Journal of Manufacturing Science and Engineering, vol. 136, no. $4,044501$.

[10] Silva H M, Noversa T, Fernandes L, Rodrigues H, Pontes A, Simulation of a transient 2D Heat transfer of an injection mold: comparison between ANSYS Workbench and ANSYS Mechanical APDL [submitted]

[11] Ahn, D G. (2011) Applications of laser assisted metal rapid tooling process to manufacture molding and forming tools. International Journal of Precision Engineering and Manufacturing 12:925-938.

[12] Zheng R, Tanner R I, Fan X-J, Injection molding: integration of theory and modeling methods. Springer Science, Business Media, 2011.

[13] Park H-S, Dang X-P (2010). Optimization of conformal cooling channels with array of baffles for plastic injection mold," International Journal of Precision Engineering and Manufacturing, vol. 11, no. 6, pp. 879-890.

[14] Meckley J, Edwards R (2009). A study on the design and effectiveness of conformal cooling channels in rapid tooling inserts," The Technology Interface Journal, vol. 10, no. 1, pp. 1-28.

[15] Feng S, Kamat A M, Pei Y (2021). Design and fabrication of conformal cooling channels in molds: Review and progress updates, International Journal of Heat and Mass Transfer 204, 124082. 
[16] Shayfull Z, Sharif S, Zain A M, Ghazali MF, Saad RM (2014). Potential of conformal cooling channels in rapid heat cycle molding: a review. Advanced Polymer Technology 33:21381-1-21381-24.

[17] Kovacs JG, Szabo F, Kovacs NK, Suplicz A, Zink B, Tabi T, Hargitai H, (2015). Thermal simulations and measurements for rapid tool inserts in injection molding applications. Applied Thermal Engineering 85:47-54.

[18] Holker R, Tekkaya E (2016). Advancements in the manufacturing of dies for hot aluminum extrusion with conformal cooling channels. International Journal of Advanced Manufacturing Technology, 83:1209-1220.

[20] Kanbur BB, Suping S, Duan F (2020). Design and optimization of conformal cooling channels for injection molding: a review. International Journal of Advanced Manufacturing Technology 106, 3253-3271. https://doi.org/10.1007/s00170-019-04697-9.

[21] Park SJ, Kwon TH (1998) Optimal cooling system design for the injection molding process. Polym Eng Sci 38:1450-1462. In Baris Burak Kanbur, Shen Suping, Fei Duan, (2020), Design and optimization of conformal cooling channels for injection molding: a review, The International Journal of Advanced Manufacturing Technology, 106:3253-3271.

[22] Lin ZC, Chou MH (2002) Design of the cooling channels in nonrectangular plastic flat injection mold. Journal of Manufacturing Systems 21:167-186.

[23] Liu Y, Gehde M (2016) Effects of surface roughness and processing parameters on heat transfer coefficient between polymer and cavity wall during the injection molding. International Journal of Advanced Manufacturing Technology 84:1325-1333.

[24] Zink B, Szabo F, Hatos I, Suplicz A, Kovacs NK, Hargitai H, Tabi T, Kovacs JG (2017) Enhanced injection molding simulation of advanced injection molds. Polymers 9:77-1-77-11.

[25]. Zhou H, Li D (2005) Mold cooling simulation of the pressing process in TV panel production. Simulation Modelling Practice and Theory 13:273-285. 
[26] Rao NS, Schumacher G, Schott NR, O'Brien KT (2002) Optimization of cooling systems in injection molds by an easily applicable analytical model. Journal of Reinforced Plastics and Composites 21:451-459.

[27] Kumar A, Ghoshdastidar P S, Muju, M K (2002). Computer simulation of transport processes during injection mold-filling and optimization of the molding conditions. Journal of Materials Processing Technology, 120(1-3), 438-449. https://doi.org/10.1016/S0924-0136(01)01211-0.

[28] Kamal MR, Mutel A T, Garcia-Rejon A , Salloum G, (1991) SPEANTEC Tech. Pap. 37483 .

[29] Holman J P, Heat Transfer, $8^{\text {th }}$ Edition, McGraw-Hill, New York, 1997.

[30] Xu X, Sachs E, Allen S, Cima M, DESIGNING CONFORMAL COOLING CHANNELS FOR TOOLING, MIT, Cambridge, MA, 1998.

[31] Silva H M , Noversa T , Fernandes L , Rodrigues H , Pontes A, Sensitivity analysis of conformal CCs for injection molds: 2D Transient Heat Transfer Analysis [submitted].

[32] Silva H M , Noversa T, Fernandes L, Rodrigues H, Pontes A, Design Optimization of conformal cooling channels for injection molds: 2D Transient Heat Transfer Analysis [submitted].

[33] Silva HM, Noversa T, Fernandes L, Rodrigues H, Pontes A, 3D Heat transfer Simulation of an injection mold: comparison between ANSYS Workbench and ANSYS Mechanical APDL [submitted].

[34] Silva HM, Noversa T, Fernandes L, Rodrigues H, Pontes A, Sensitivity analysis of conformal CCs for injection molds: 3D Transient Heat Transfer Analysis [submitted].

[35] Silva HM, Noversa T, Fernandes L, Rodrigues H, Pontes A, Design Optimization of conformal cooling channels for injection molds: 3D Transient Heat Transfer Analysis [submitted]. 